Proc. Indian Acad. Sci. (Earth Planet. Sci.), Vol. 101, No. 3, September 1992, pp. 227-238. (C) Printed in India.

\title{
Application of pattern recognition algorithm in the seismic belts of Indian convergent plate margin - $\mathrm{CN}$ algorithm
}

\author{
V K GAHALAUT ${ }^{1,2}$, I V KUZNETSOV ${ }^{1,3}$, I M ROTWAIN ${ }^{1,3}$, \\ A M GABRIELOV ${ }^{1,3}$ and V I KEILIS-BOROK \\ ${ }^{1}$ International Institute for Earth, Environmental and Marine Sciences (IIEM) Galileo Guest \\ House, P. Box. 586, 34100 Trieste, Italy \\ ${ }^{2}$ Department of Earth Sciences, University of Roorkee, Roorkee 247667 U. P., India \\ ${ }^{3}$ International Institute of Earthquake Prediction Theory and Mathematical Geophysics, \\ Academy of Sciences of the USSR, Warshavskoye sh. 79, k2 Moscow 113 556, USSR
}

MS received 27 April 1992; revised 21 July 1992

\begin{abstract}
The earthquake catalogue from 1964 to August 1991 is used to identify the times of increased probabilities (TIPs) of the earthquake mainshocks of magnitudes greater than or equal to 6.4 and are associated with the Indian convergent plate margins, in retrospect. In Pakistan and Indo-Burma regions, the analysis was repeated for magnitude threshold 6.2 and 7.0 respectively. All the earthquakes (except one in the Hindukush region and one in IndoBurmese region) in Pakistan, Hindukush-Pamir, Himalaya and Indo-Burmese regions were preceded by the special activation and hence were predicted.

Approximately $23 \pm 10 \%$ of the total time (1970 to August 1991) is occupied by the TIPs in all the regions. The reasons for failure to predict the two earthquakes in these regions are discussed.

Our analysis gives a better picture of the regionalization and the size of the space-time volume for the preparation of an earthquake. The high success ratio of the algorithm proves that it can be applied in this territory for further prediction in the real time, without any significant changes in its parameters.
\end{abstract}

Keywords. Intermediate term prediction; CN algorithm; times of increased probability; regionalization.

\section{Introduction}

Considering the self similar nature of the earthquakes in different tectonic environments, an attempt to develop an algorithm, based on the pattern recognition technique, was introduced by Allen et al (1984) and Keilis-Borok and Rotwain (1990), and the so developed algorithm was named as CN (for California Nevada, as for the first time it was successfully applied there). Later on it was successfully applied in the different seismic belts of the world (Keilis-Borok and Rotwain 1990 and Gabrielov et al 1986).

In this study we have applied this algorithm in the seismic beits associated with the Indian convergent plate margins (figure 1). The almost NNE $\left(\mathrm{N} 15^{\circ}-20^{\circ} \mathrm{E}\right)$ movement of the Indian plate and its convergence with the Eurasian plate, make the earthquakes to occur along its margins in Pakistan, Hindukush-Pamir, Himalaya and IndoBurmese mountain chains. Here, our purpose is to investigate the applicability of $\mathrm{CN}$ algorithm to the retrospective prediction of strong mainshocks (common maximum magnitude greater than or equal to 6.4 ) in the regions, mentioned above, which 


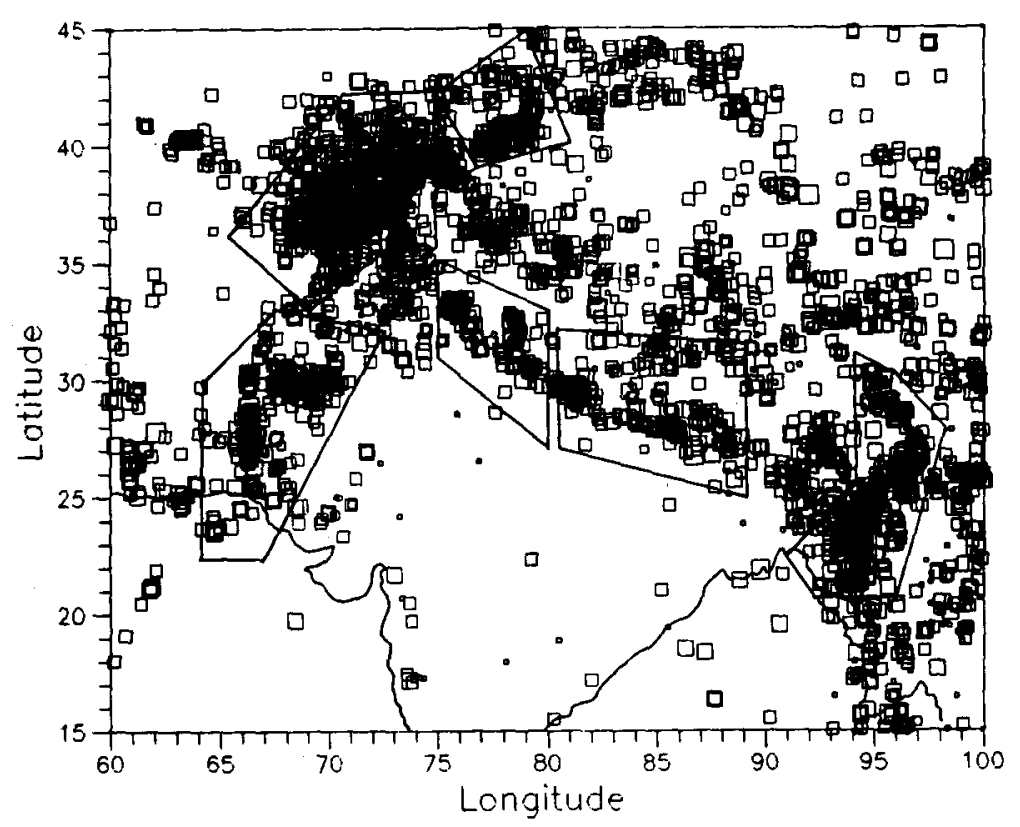

Figure 1. Seismicity associated with the Indian plate convergent margins, all the shallow mainshocks of the period 1970 to August 1991 are plotted here, the smallest square indicates the magnitude $0-3$ and then the increase in the size of square corresponds to the increase in magnitude by one unit.

occurred at the shallow level (depth less than $100 \mathrm{~km}$ ) in the period from 1970 to August 1991 (table 1). For this purpose we have used the mainshocks from NEIC (from 1964 till end of 1990) and PDE (from January 1991 till August 1991) catalogues in which the aftershocks were removed using the time and space windows given by Keilis-Borok et al (1980).

\section{2. $\mathrm{CN}$ algorithm}

Here we give a brief description of the $\mathrm{CN}$ algorithm, which is based on the searching of the anomalous variations of earthquakes flow. A more detailed description can be found in Keilis-Borok et al (1988) and Keilis-Borok and Rotwain (1990).

Parameters of seismicity (traits) are represented by function of time, defined on a sequence of mainshocks in the region within a sliding time window. The following traits are considered: intensity of earthquake flow (level of seismic activity), its temporal variation, clustering in time and space, their concentration in space.

Different functions may correspond to different traits or to the same trait with different values of numerical parameters (range of magnitudes, length of time window etc.). The earthquake flow at each moment is represented by a vector of the values of these functions. Now we know the values of functions at given moment $t$ and we want to know whether the time interval $(t, t+\tau)$ belongs to a TIP of a main shock or a foreshock with $M \geqslant M_{0}$, here $\tau$ is a numerical parameter.

Considering the self similarity of earthquake flow the functions are normalized so that their definition can be applied uniformally to regions of different size and 
seismicity. Normalization is achieved by the choice of magnitude range $\underline{M} \leqslant M \leqslant \bar{M}$, for the earthquakes considered.

In the definition of some functions, earthquakes are counted with equal weight, independent of their magnitude. To normalize these functions, we define $\underline{M}$ by the following condition: the average annual number of earthquakes with $M \geqslant \underline{M}$ in the region considered is equal to a constant $n(\underline{M})$, which is common for all regions. In this way the intensities of earthquake flows are equalized. In the determination of other functions, earthquakes are weighted depending on their magnitude. To normalize these functions, we define magnitude threshold as $\left(M_{0}-c\right)$, where $c$ is a numerical parameter.

The first stage is the learning stage where we identify the TIPs. For this purpose the history of each territory is divided into two parts: the $D$ (or dangerous) time intervals, which immediately precede each strong earthquake and therefore include TIPs and the $N$ (or non-dangerous) time intervals, which occupy the remainder of time. The duration of the $D$ intervals is taken to be two years. The three year intervals of $N$ type after each strong earthquake were not used in learning, to avoid complications connected with high residual activity, which is not completely suppressed by removal of aftershocks. These learning sets were used to define the threshold for discretization of the functions. The characteristic $D$ and $N$ features for California have been used for this study.

In an effort to make the range of values of each function robust, we discretize it by dividing it into three intervals, small (S), medium (M) and large (L). The value of each function is represented by a binary code that indicates whether it is in the $\mathrm{S}, \mathrm{M}$ or $\mathrm{L}$ range. In this way the vector of functions is represented by short binary code. At the next stage we define the characteristic features of the objects $D$ and $N$, i.e. TIPs and nonTIPs for a given region. Features $D$ are defined by the condition that they are encountered sufficiently often in objects $D$ and sufficiently seldom in objects $N$. Features $N$ are defined by the reverse condition. For detailed definitions Gelfand et al (1976) may be referred.

To diagnose TIPs we count the number of $D$ and $N$ features at sample times over consecutive intervals in each region. Let $n_{D}(t)$ and $n_{N}(t)$ be the numbers of $D$ and $N$ features at time $t$ and define $\bar{\Delta}(t)=n_{D}-n_{N}$. If $\bar{\Delta}$ is sufficiently large (standard value is 5 ), the particular time is likely to be $D$ interval, this is the first condition. The second condition is

$$
\sigma(t)=10^{-\beta\left(M_{0}-\alpha\right)} \Sigma 10^{\beta\left(M_{i}-\alpha\right)}<\bar{\Sigma}=4 \cdot 9,
$$

where $\beta=1, \alpha=4 \cdot 5, M_{i} \leqslant M_{0}-0 \cdot 1$ and $\sigma(t)$ estimates the total fracture area for three preceding years.

The TIP lasts a year, consecutive TIPs may overlap and prolong each other. If no strong earthquake occurred during the TIP, it is called false alarm, strong earthquake which was not preceded by a TIP, is a failure to predict.

\section{Results and discussions}

We divide the plate margins in four different regions based upon the process and the mechanism of the earthquake occurrence there. The four regions which were further divided in subregions (figure 2) taking into account that the spatial distribution of earthquakes and the boundaries should not cross clouds of epicenters, are Pakistan 


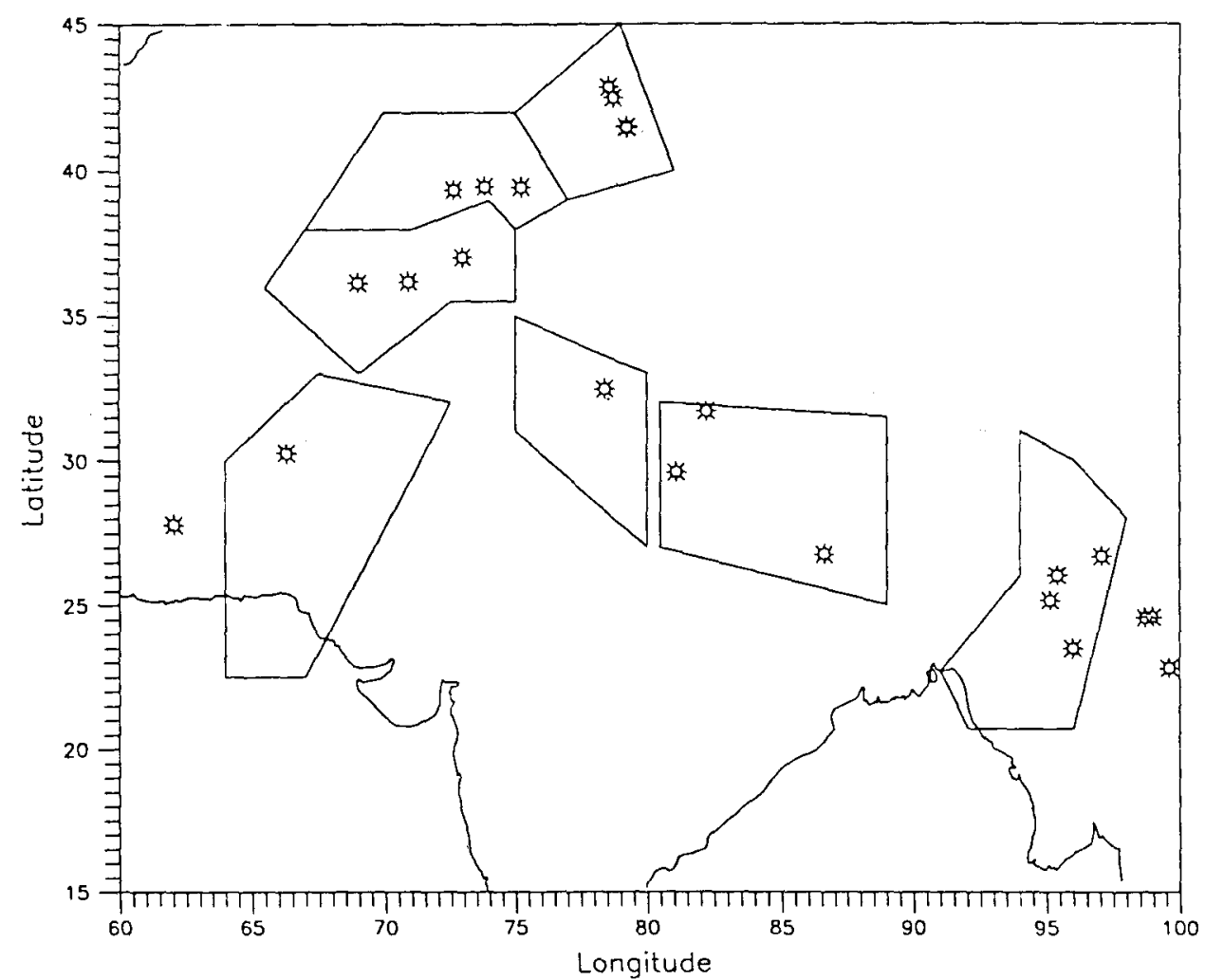

Figure 2. This figure shows the regionalization in the different seismic belts. Stars indicate the mainshocks of $M \geqslant 6.4$ that occurred after 1970 .

region, the Hindukush-Pamir region, the Himalayan region and the Indo-Burmese region. In the Hindukush-Pamir region Gabrielov et al (1986) applied the algorithm using a local catalogue for the period 1960 to 1986 . The results of this study were encouraging as all the mainshocks $\left(M_{0}=6 \cdot 4\right)$, that occurred after 1966 were preceded by the TIPs. Here in this work we tried to check the applicability of the standard catalogue, an entirely new regionalisation and also updating of the results.

In regions 3 and 4 Bhatia et al (1990) applied the algorithm to diagnose the TIPs for the strong mainshocks, that occurred after 1970 till 1989. They used the transformed magnitudes $\left(M_{s}=2 m_{b}-5 \cdot 34\right)$. They diagnose TIPs for all the four earthquakes in the region 3 and found one current TIP in the eastern segment of it. In region 4 they missed the earthquake of 1970 but successfully predicted the earthquake of 1988 . Our work uses the common maximum magnitudes, suggests a new regionalization in region 4 and updates the results of Bhatia et al (1990).

In the following paragraphs we discuss the results of the application of the CN algorithm in the above regions.

\subsection{Pakistan region}

The earthquakes are mainly confined to the narrow seismic belt which runs almost parallel and slightly east of NNE trending Chaman fault. Since 1970, only one 
earthquake of magnitude more than 6.4 occurred in 1975. Figure 3(i) shows the successful TIP for the event, using $\bar{\Delta}$ as 5 and $\bar{\Sigma}=4.9$. The TIPs occupy 114 months (44.2\% time), which can be further narrowed down to $37 \cdot 1$ months $(14.4 \%$ time) using $\bar{\Delta}$ and $\bar{\Sigma}$ as 7 and 1.4 respectively at the cost of current alarm (figure 4(i)). In this region an earthquake of magnitude 6.2 occurred in 1990 . We repeated our analysis using the magnitude threshold $M_{0}$ as 6.2 with a view that only one earthquake may not be sufficient to establish a recognition rule. Now both the earthquakes are predicted using the standard values of $\bar{\Delta}$ and $\bar{\Sigma}$ (figure 3(ii)). TIPs occupy 322.0 months $(47 \cdot 3 \%)$ which can be decreased to a minimum of $58.6(22.7 \%)$ months at the cost of current alarm, using $\bar{\Delta}$ and $\bar{\Sigma}$ as 7 and 2.0 respectively (figure 4 (ii)). We believe that the cause of the current alarm is the activation produced by this recent earthquake of 1990 , as the current TIP disappears like the other false alarms with $\bar{\Delta}$ and $\bar{\Sigma}$ as 7 and $2 \cdot 0$ respectively, so we diagnose this as a false alarm.

\subsection{Hindukush-Pamir region}

Here exists two distinct belts of seismicity, the southern belt of a deeper level and the northern one of shallower seismicity only (figure 5). The annual seismicity rate of earthquake occurrence is higher as compared to nearby regions of Pakistan and Central Himalaya. In the eastern part of this region, the rate is comparatively lower. These features of the belts provide help in making regionalization of three different subregions (figure 2 ).

In the southern subregion (figure 2) the TIPs preceded all the three earthquakes (figure 3(iii)). The total volume occupied by the TIPs is 118.8 months $(46.0 \%)$ with standard values of $\bar{\Delta}$ and $\bar{\Sigma}$. A current alarm is also diagnosed in the region. The successful TIPs and the current TIPs are stable with $\bar{\Delta}$ and $\bar{\Sigma}$ as 6 and 4.9 respectively (figure 4(iii)). Now the total volume occupied by the TIPs is reduced to 84.8 months $(32.9 \%)$.

In the northern belt two out of three earthquakes were predicted. The earthquake of 1974 gives the failure to predict but at the same time, in the southern region (discussed above) there is an alarm which is diagnosed as false TIP there. The TIPs occupy 57.7 months $(22.4 \%$ ) with the standard values of $\bar{\Delta}$ and $\bar{\Sigma}$ (figure 3(iv)) which is further reduced to 39.7 months $(15.4 \%)$ if $\bar{\Delta}$ and $\bar{\Sigma}$ are taken as 5 and 2.5 respectively (figure 4(iv)).

In the eastern part of this region all the earthquakes are predicted with standard $\bar{\Delta}$ and $\bar{\Sigma}, 68.4$ months $(24.3 \%)$ are used by the TIPs (figure $3(\mathrm{v})$ ). For $\bar{\Delta}=6$ and $\bar{\Sigma}=4.9$ and the volume of time, occupied by the TIPs is reduced to 58.4 months or $20.7 \%$ time of analysis (figure $4(v)$ ).

Looking at almost the same level of seismicity we tried to study the southern and northern subregions together, i.e. using the same threshold for discretization of functions. For $\bar{\Delta}=5$ and $\bar{\Sigma}=4.9$, the TIPs occupy $118.8(46.0 \%)$ and $57.6(22.3 \%)$ months in southern and northern regions respectively (figure $6(\mathrm{i}) \&$ (ii)). The current TIP still exists in the southern region. The results are stable with $\bar{\Delta}=6$ and now the TIPs occupy $86.8(33.6 \%)$ and $57.6(22.3 \%)$ months in the southern and northern regions respectively (figure 7 (i) \& (ii)).

\subsection{Himalayan region}

This region is further divided into two subregions, namely the western and the eastern 

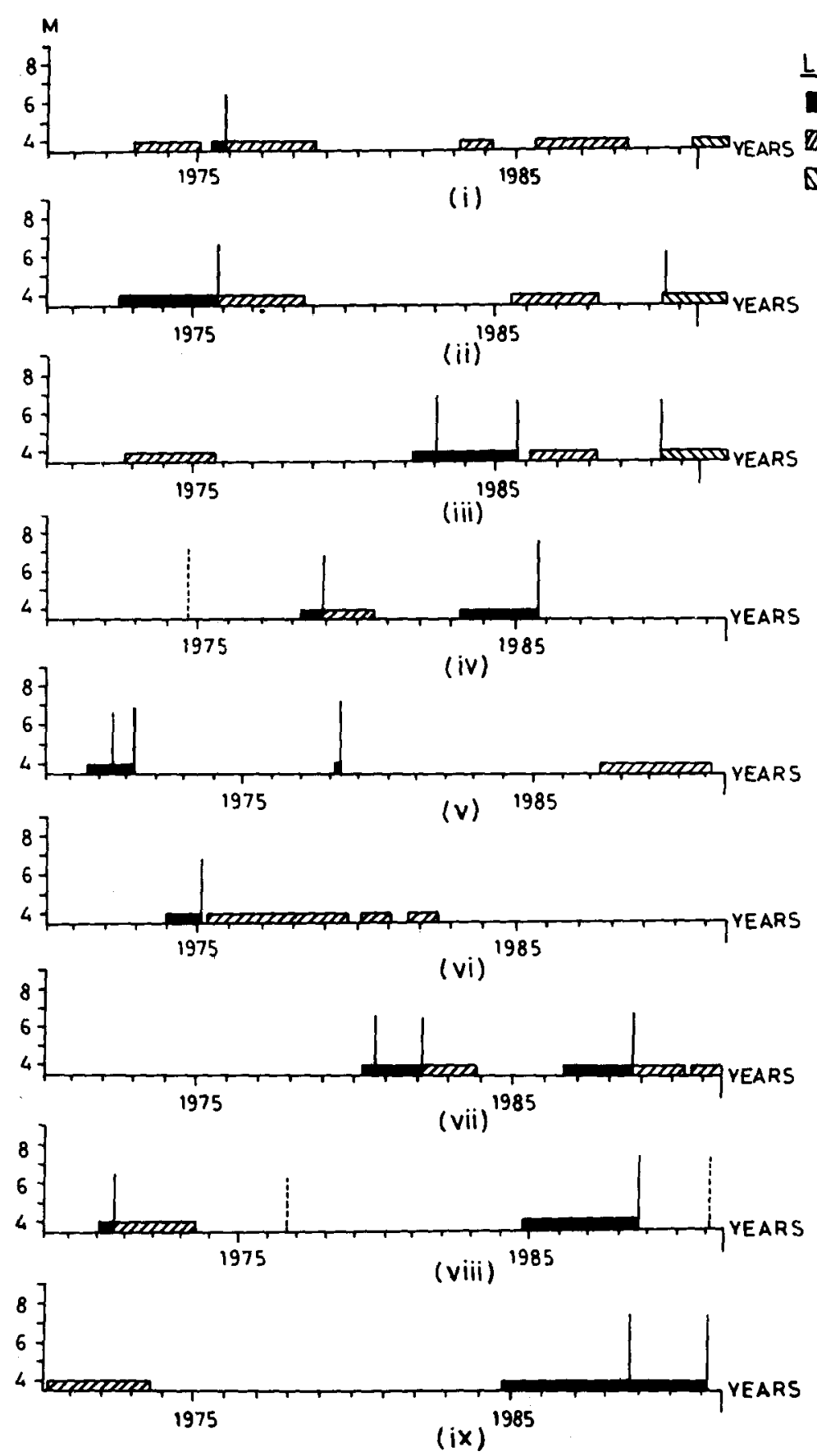

Figure 3. TIPs in the regions with standard thresholds of $\bar{\Delta}$ and $\bar{\Sigma} . M_{0}$ is $6 \cdot 4$, if not mentioned specifically. i) Pakistan region, ii) Pakistan region, $M_{0}=6 \cdot 2$, iii) Hindukush Pamir, southern region, iv) Hindukush Pamir, northern region, v) Hindukush Pamir, eastern region, vi) Himalayan, western region, vii) Himalayan, eastern region, viii) Indo-Burmese region and ix) Indo-Burmese region, $M_{0}=7 \cdot 0$.
LEGEND :-

SUCCESS TIP

WIID FALSE TIP

DIV CURRENT ALARM

1 PREDICTED

: FAILURE 

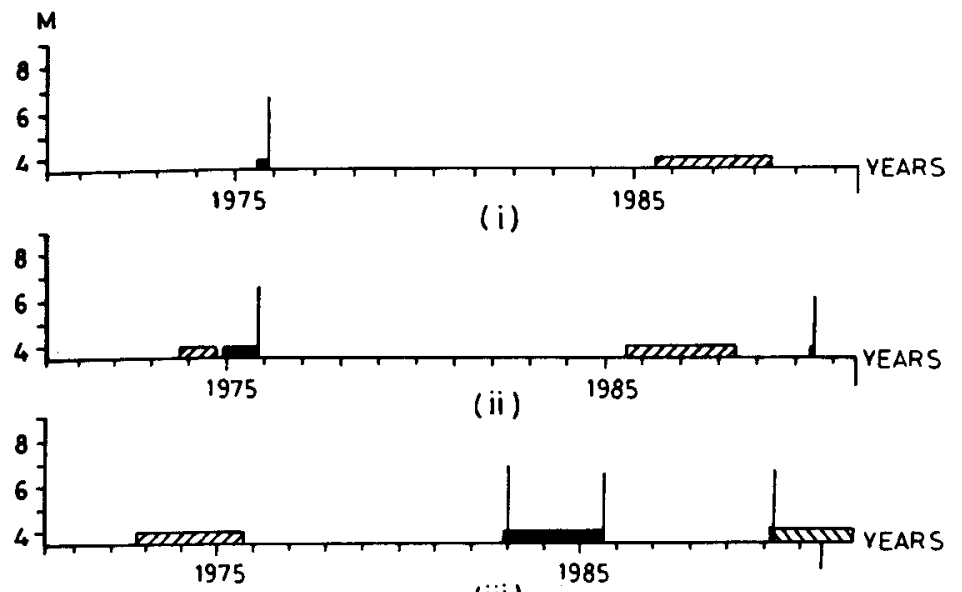

(iii)
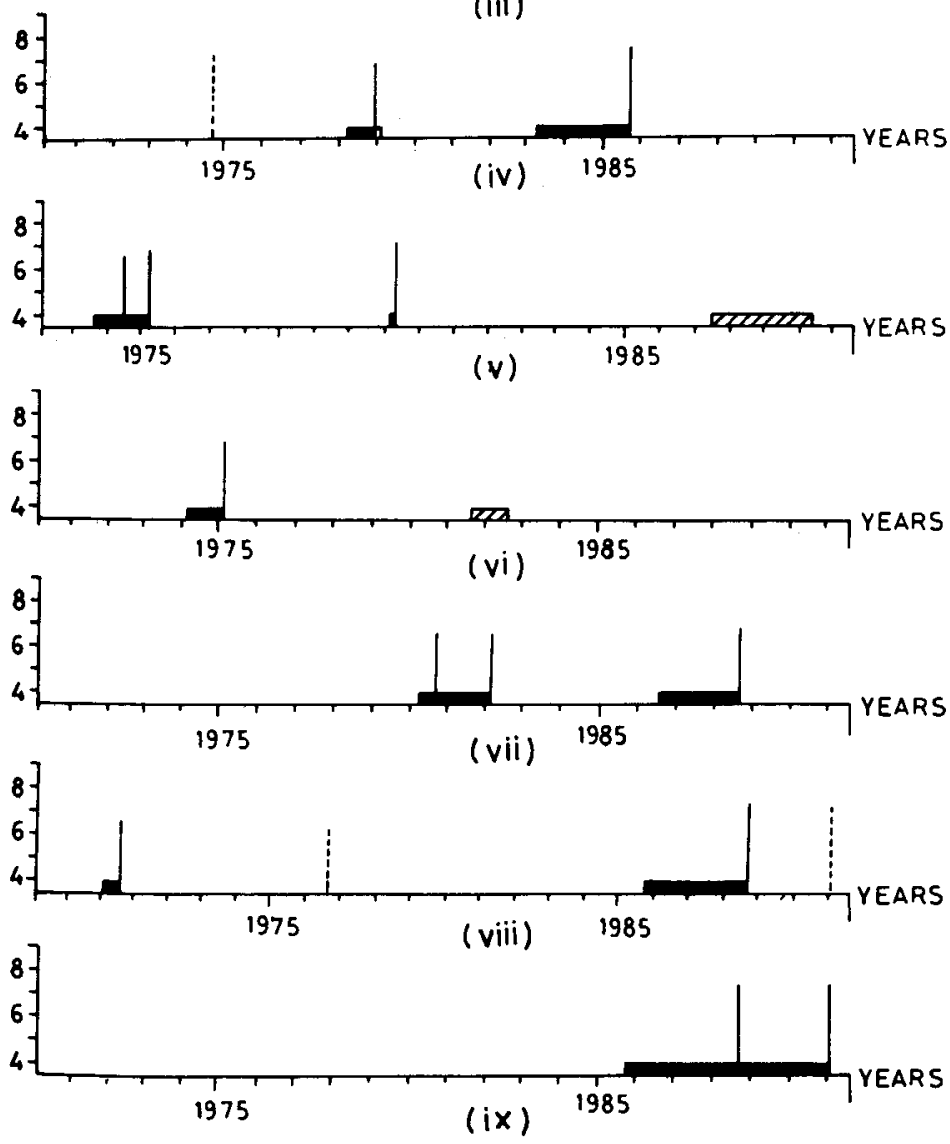

Figure 4. Best results obtained by changing the thresholds. $M_{0}=6 \cdot 4$, if it is not mentioned specifically i) Pakistan region, $\bar{\Delta}=7$ and $\bar{\Sigma}=1 \cdot 3$, ii) Pakistan region, $M=6 \cdot 2, \bar{\Delta}=7$ and $\bar{\Sigma}=2 \cdot 0$, ii) Hindukush Pamir, southern region, $\bar{\Delta}=6$ and $\bar{\Sigma}=4.9$, iv) Hindukush Pamir, northern region, $\bar{\Delta}=5$ and $\bar{\Sigma}=4 \cdot 2$, v) Hindukush Pamir, eastern region, $\bar{\Delta}=6$ and $\bar{\Sigma}=4.9$, vi) Himalayan, western region, $\bar{\Delta}=6$ and $\bar{\Sigma}=3 \cdot 0$, vii) Himalayan, eastern region, $\bar{\Delta}=6$ and $\bar{\Sigma}=3.5$, viii) Indo-Burmese region, $\bar{\Delta}=6$ and $\bar{\Sigma}=1 \cdot 7$ and ix) Indo-Burmese region, $M_{0}=7 \cdot 0$, $\bar{\Delta}=7$ and $\bar{\Sigma}=4.9$.
LEGEND:-

SUCCESS TIP

EZD FALSE TIP

DIV CURRENT ALARM

I PREDICTED

FAILURE

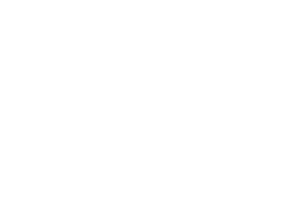




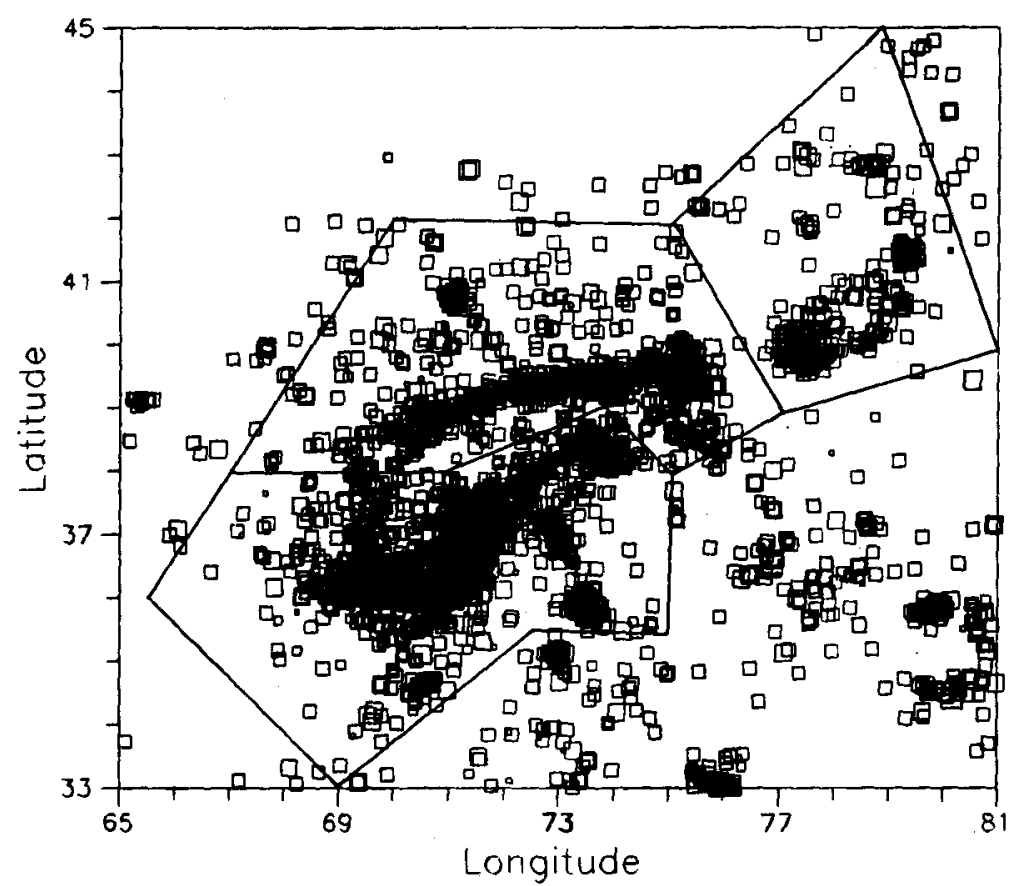

Figure 5. Two distinct belts of seismicity in the Hindukush-Pamir region. The regionalization used in the study is also shown.

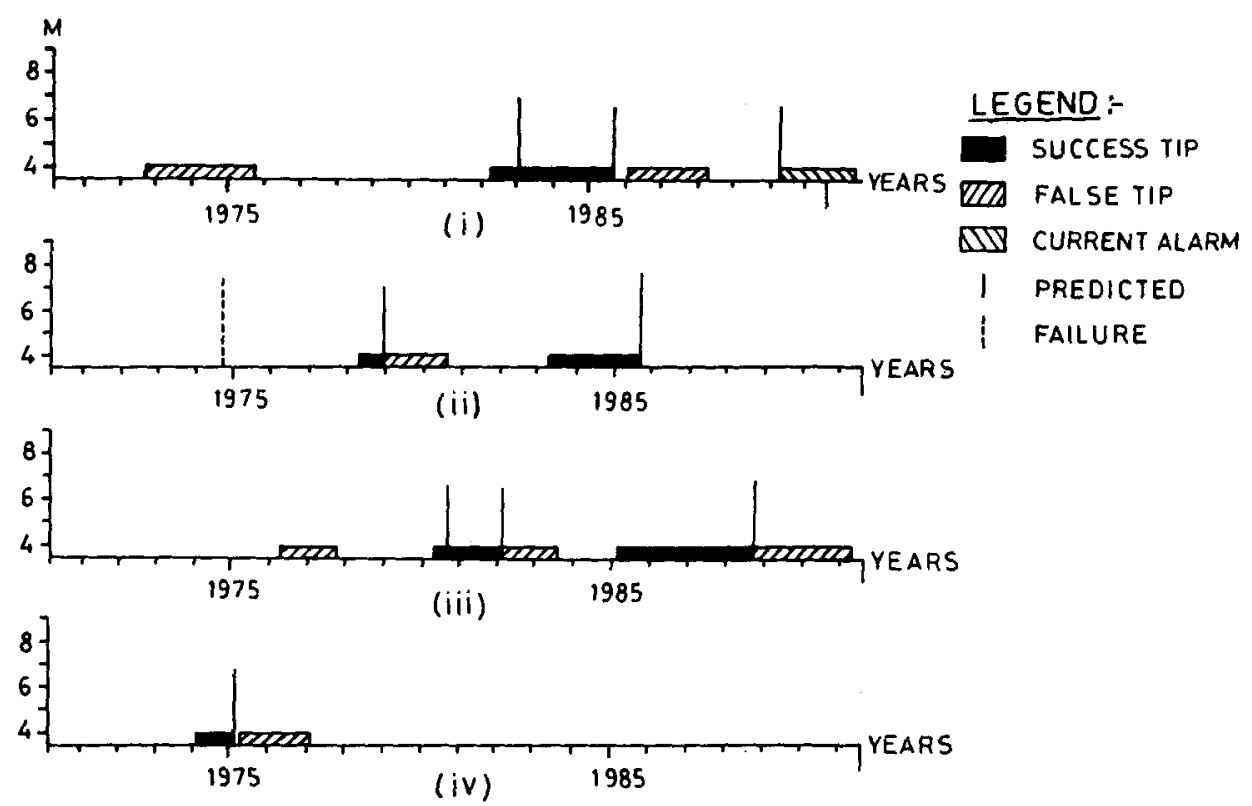

Figure 6. The TIPs in the i) and ii) Hindukush Pamir, southern and northern region iii) and iv) Himalayan, eastern and western region with standard thresholds of $\bar{\Delta}$ and $\bar{\Sigma}$. 


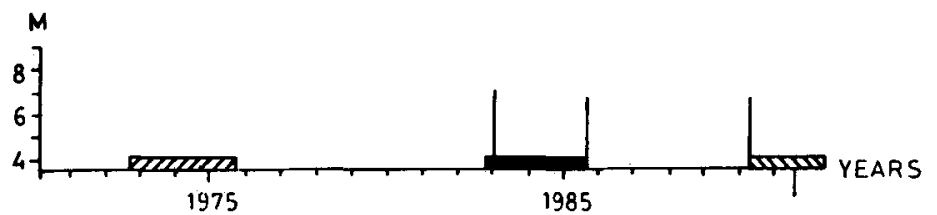

(i)
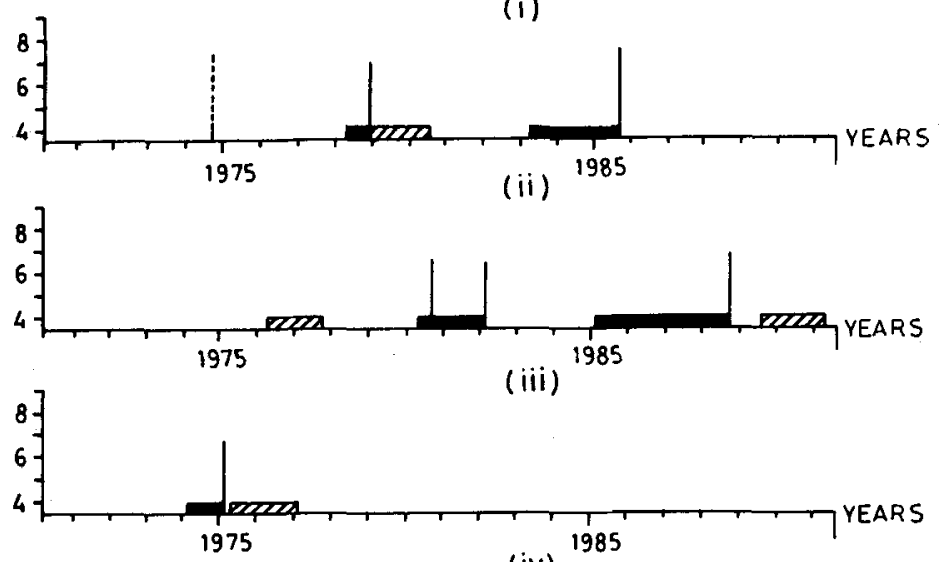

(ii)

(iii)

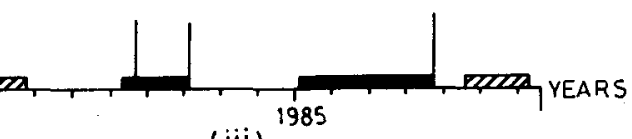

\section{LEGEND:-}

SUCCESS TIP

WIA FALSE TIP

NIV CURRENT ALARM

I PREDICTED

FAILURE

Figure 7. The TIPs in the i) and ii) Hindukush Pamir southern and northern region, $\bar{\Delta}=6$ and $\bar{\Sigma}=4.9$, iii) and iv) Himalayan, eastern and western region, $\bar{\Delta}=5$ and $\bar{\Sigma}=3.5$.

subregion (figure 2). In this region the seismicity level is very low. Most of the diffused seismicity is confined between the Main Central Thrust and the Main Frontal Thrust. In the western subregion the earthquake of 1975 shows the TIP along with some false alarms. For $\bar{\Delta}=5$ and $\bar{\Sigma}=4 \cdot 9$, the TIPs occupy 92 months or $35.7 \%$ time (figure $3($ vi)). The time volume occupied by the TIPs can be narrowed down to 24.0 months $(9 \cdot 3 \%)$ using $\bar{\Delta}$ as 6 and $\bar{\Sigma}=3 \cdot 0$ (figure $4($ vi)).

In the eastern subregion all the three earthquakes are followed by the TIPs and the time volume occupied by them is 102 months $(39.5 \%)$ using $\bar{\Delta}=5$ and $\bar{\Sigma}=4.9$ (figure 3(vii)). With $\bar{\Delta}=6$ and $\bar{\Sigma}=3 \cdot 5$, the time volume occupied by the TIPs is reduced to just 48.4 months or $18.7 \%$ time (figure 4 (vii)).

Considering the similarity in the process of earthquake occurrence in these two subregions and also considering that in the western subregion, there is only one earthquake and hence it may not be suitable to establish a recognition rule, we analyze these two regions together i.e. using the common thresholds for the discretization of the functions for both the regions. For $\bar{\Delta}=5$ and $\bar{\Sigma}=4.9$ the TIPs occupy $34(13.2 \%)$ and 132 months $(51 \cdot 2 \%$ ) in the two subregions (figure 6(iii) \& (iv)). For $\bar{\Sigma}=3 \cdot 2$, TIPs occupy $38(15.4 \%)$ and 103.2 months $(40.0 \%)$ in the eastern and western subregions, respectively (figure 7 (iii) \& (iv)).

\subsection{Indo Burmese region}

This region is characterized by high and deep level seismicity. The regionalization is all along the seismicity associated with the almost N-S trending Arakan Yoma fault system which are mainly strike slip in nature with slight component of thrust motion.

Four strong earthquakes occurred during the span of the catalogue in the region. 
The earthquake of 1976 was not preceded by the TIP. The reason may be the following. The $m_{b}$ for the earthquake that occurred on 12.8 .76 is 6.4 (table 1 ), whereas the $m_{s}$ for the same is 6.1. Considering the empirical relation between $m_{b}$ and $m_{s}$, this seems to be unusual. As in this study we have chosen the common maximum magnitude, this earthquake is considered as strong shock, which may not be true. Moreover the energy released by the earthquake seems to be small and hence it may not be treated as strong shock.

After the earthquake of $1988\left(m_{\max }=7.3\right)$, in the vicinity of this, another earthquake occurred on 5.1.91 $\left(m_{\max }=7 \cdot 3\right)$. Because we are using the SIGMA (with a less threshold of $M_{0}(=6 \cdot 4)$, to terminate the TIP after the strong shock, it is not preceded by the TIP. But when we used $M_{0}$ as $7 \cdot 0$, the earthquake is successfully predicted.

For the standard values of $\bar{\Delta}$ and $\bar{\Sigma}$ and $M_{0}$ as 6.4, the TIPs occupy 89.2 months or $31.6 \%$ time (figure 3(viii)). All the false alarm can be deleted using $\bar{\Delta}$ and $\bar{\Sigma}$ as 6 and 1.7 , without any loss to successful TIPs. Now the TIPs occupy $42 \cdot 1$ months or in other words $14.9 \%$ time of analysis (figure 4 (viii)). In the second case where $M_{0}$ is taken as 7.0 the TIPs preceded both the earthquakes of 1988 and 1991. With the standard $\bar{\Delta}$ and $\bar{\Sigma}$ 116 months $(45 \%$ ) are occupied by the TIPs (figure 3(ix)). The successful TIPs are stable

Table 1. The time, location, depth and the four magnitudes of the strong mainshocks (from the NEIC catalogue) are given in the table, occurred in between 15 and $45^{\circ}$ latitudes and 60 and $100^{\circ}$ longitudes. The events marked with $*$ lie outside the proposed regionalizations. The event marked with \# lies in Pakistan region and has the $m_{\max }=6.1$ (discussed in the text).

\begin{tabular}{|c|c|c|c|c|c|c|c|c|c|c|c|}
\hline Year & Month & Day & Hour & Minute & Lat & Long & Depth & $m_{b}$ & $m_{s}$ & $m_{l}$ & $m_{p}$ \\
\hline 1970 & 6 & 5 & 4 & 53 & $42 \cdot 48$ & $78 \cdot 76$ & 20 & 6.00 & $6 \cdot 60$ & 0.00 & 6.50 \\
\hline 1970 & 7 & 29 & 10 & 16 & 26.02 & 95.40 & 59 & 6.50 & 0.00 & $0-00$ & 6.40 \\
\hline 1971 & 3 & 23 & 9 & 52 & $41 \cdot 49$ & $79 \cdot 26$ & 0 & $5 \cdot 70$ & 0.00 & 0.00 & 6.80 \\
\hline 1971 & 3 & 23 & 20 & 47 & $41 \cdot 45$ & $79 \cdot 26-$ & 0 & 600 & 5.80 & 0.00 & 6.90 \\
\hline *1971 & 3 & 24 & 13 & 54 & 35.46 & $98 \cdot 17$ & 13 & $5 \cdot 80$ & $6 \cdot 40$ & 0.00 & 000 \\
\hline *1973 & 7 & 14 & 4 & 51 & $35 \cdot 18$ & 86.48 & 0 & $6 \cdot 00$ & 6.90 & 0.00 & 6.70 \\
\hline 1974 & 8 & 11 & 1 & 13 & $39 \cdot 45$ & 73.83 & 9 & 6.40 & $7 \cdot 30$ & 0.00 & 6.90 \\
\hline 1975 & 1 & 19 & 8 & 2 & 32.45 & $78 \cdot 43$ & 33 & $6 \cdot 20$ & 6.80 & 0.00 & $6 \cdot 80$ \\
\hline 1975 & 10 & 3 & 5 & 14 & 30.25 & $66 \cdot 31$ & 11 & $5 \cdot 80$ & 6.70 & 0.00 & 6.70 \\
\hline *1976 & 4 & 8 & 2 & 40 & $40 \cdot 31$ & 63.77 & 33 & 6.50 & 7.00 & 000 & $7 \cdot 10$ \\
\hline 1976 & 5 & 29 & 12 & 23 & $24 \cdot 57$ & 98.95 & 8 & $6 \cdot 10$ & 6.90 & 0.00 & 6.90 \\
\hline 1976 & 5 & 29 & 14 & 0 & $24 \cdot 53$ & $98 \cdot 71$ & 10 & $6 \cdot 00$ & 7.00 & 0.00 & 6.90 \\
\hline 1976 & 8 & 12 & 23 & 26 & $26 \cdot 68$ & 97.07 & 27 & 6.40 & $6 \cdot 10$ & 0.00 & 000 \\
\hline *1977 & 11 & 18 & 5 & 20 & 32.69 & $88 \cdot 38$ & 33 & $5 \cdot 70$ & 6.50 & 0.00 & $6 \cdot 30$ \\
\hline 1978 & 3 & 24 & 21 & 5 & $42 \cdot 83$ & 78.60 & 33 & $6 \cdot 20$ & $7 \cdot 10$ & 0.00 & 0.00 \\
\hline 1978 & 11 & 1 & 19 & 48 & 39.34 & 72.61 & 40 & $6 \cdot 20$ & 6.80 & $0-00$ & 6.80 \\
\hline 1980 & 7 & 29 & 14 & 58 & 29.59 & 81.09 & 18 & $6 \cdot 10$ & 6.50 & 0.00 & 6.60 \\
\hline 1982 & 1 & 23 & 17 & 37 & 31.69 & $82 \cdot 24$ & 33 & 6.00 & 6.50 & 0.00 & $6 \cdot 20$ \\
\hline 1982 & 12 & 16 & 0 & 40 & $36 \cdot 14$ & 69.01 & 36 & $6 \cdot 20$ & 6.60 & $0-00$ & 6.90 \\
\hline *1983 & 4 & 18 & 10 & 58 & $27 \cdot 79$ & 62.05 & 64 & 6.50 & 0.00 & $0-00$ & 6.50 \\
\hline *1984 & 3 & 19 & 20 & 28 & 40.32 & 63.35 & 15 & 6.50 & 7.00 & 0.00 & $7 \cdot 10$ \\
\hline 1985 & 7 & 29 & 7 & 54 & $36 \cdot 19$ & 70.89 & 99 & 6.60 & $0-00$ & 0.00 & 0.00 \\
\hline 1985 & 8 & 23 & 12 & 41 & 39.43 & $75 \cdot 22$ & 7 & $6 \cdot 40$ & $7 \cdot 30$ & $0-00$ & 7.50 \\
\hline *1986 & 8 & 20 & 21 & 23 & $34 \cdot 57$ & 91.63 & 33 & $5 \cdot 40$ & 6.50 & 0.00 & 0.00 \\
\hline 1988 & 8 & 6 & 0 & 36 & $25 \cdot 15$ & $95 \cdot 13$ & 91 & 6.80 & $7 \cdot 20$ & $7 \cdot 30$ & 0.00 \\
\hline 1988 & 8 & 20 & 23 & 9 & $26 \cdot 75$ & 86.62 & 57 & $6 \cdot 40$ & 6.60 & 6.80 & 6.50 \\
\hline 1988 & 11 & 6 & 13 & 3 & $22 \cdot 79$ & 99.61 & 18 & $6 \cdot 10$ & $7 \cdot 30$ & 7.00 & 6.90 \\
\hline \#1990 & 3 & 4 & 19 & 46 & $28 \cdot 87$ & $66 \cdot 34$ & 28 & $5 \cdot 70$ & $6 \cdot 10$ & 0.00 & 0.00 \\
\hline 1990 & 3 & 25 & 14 & 17 & 37.01 & 72.95 & 32 & 6.00 & $6 \cdot 70$ & 0.00 & 0.00 \\
\hline 1991 & 1 & 5 & 14 & 57 & 23.47 & 95.98 & 20 & $6 \cdot 30$ & $7 \cdot 10$ & 0.00 & $7 \cdot 30$ \\
\hline
\end{tabular}


even with $\bar{\Delta}$ as 7 and the false TIP disappears (figure 4(ix)), now the TIPs occupy 64 months $(24 \cdot 8 \%)$.

\section{Conclusions}

From the above analysis we conclude that all the earthquakes during 1970 till August 1991, except one in Hindukush and one in the Indo-Burmese region, were preceded by the TIPs. The reason of failure to predict the earthquake in Indo-Burmese region is because of the catalogue limitations. The unpredictable earthquake of 1974 in the northern subregion of Hindukush shows the false alarm in the nearby southern subregion which may be treated as successful TIP for the same. A current alarm is diagnosed in the southern belt of Hindukush-Pamir region. This makes the study more important and recommends that the study should be repeated again with the updated catalogue, to comment on the status of the current TIP.

The results in this territory are stable as seen from the changing value of voting $(\bar{\Delta})$ and a slight change in the regionalization. A complete summary of statistics about

Table 2. Complete statistics of the results for the standard values of $\bar{\Delta}$ and $\bar{\Sigma}$.

\begin{tabular}{|c|c|c|c|c|c|}
\hline \multicolumn{2}{|c|}{ No. Territory } & \multirow{2}{*}{$\frac{M_{0}}{6.4}$} & \multirow{2}{*}{$\begin{array}{c}\begin{array}{c}\text { Strong earthquakes } \\
\text { within TIPs/Total }\end{array} \\
1 / 1\end{array}$} & \multirow{2}{*}{$\begin{array}{c}\begin{array}{c}\text { Total duration } \\
\text { of TIPs(months) } \\
\text { and } \% \text { time }\end{array} \\
114.0 \text { or } 44 \cdot 2 \%\end{array}$} & \multirow{2}{*}{$\begin{array}{c}\begin{array}{c}\text { Duration of TIPs } \\
\text { per earthquake } \\
\text { (months) and } \% \text { time }\end{array} \\
114.0 \text { or } 44.2 \%\end{array}$} \\
\hline 1. & Pakistan & & & & \\
\hline & Pakistan & $6 \cdot 2$ & $2 / 2$ & 122.0 or $47.3 \%$ & 61.0 or $23.7 \%$ \\
\hline 2. & Hindukush S & 6.4 & $3 / 3$ & 118.8 or $46.0 \%$ & 39.6 or $15.3 \%$ \\
\hline 3. & Hindukush $\mathbf{N}$ & 6.4 & $2 / 3$ & 57.7 or $22.4 \%$ & 19.2 or $7.5 \%$ \\
\hline 4. & Hindukush E & $6 \cdot 4$ & $4 / 4$ & 68.4 or $24.3 \%$ & $17 \cdot 1$ or $6.1 \%$ \\
\hline 5. & Himalaya W & $6 \cdot 4$ & $1 / 1$ & 92.0 or $35.7 \%$ & 92.0 or $35.7 \%$ \\
\hline 6. & Himalaya E & 6.4 & $3 / 3$ & 102.0 or $39.5 \%$ & 34.0 or $13.2 \%$ \\
\hline \multirow[t]{2}{*}{7.} & Indo-Burma & 6.4 & $2 / 4$ & 89.0 or $31.6 \%$ & $22 \cdot 2$ or $7.9 \%$ \\
\hline & Indo-Burma & 7.0 & $2 / 2$ & 116.0 or $45.0 \%$ & 58.0 or $22.5 \%$ \\
\hline
\end{tabular}

Table 3. Improved statistics of the results, using the best suited values of $\bar{\Delta}$ and $\bar{\Sigma}$ (not standard). See text.

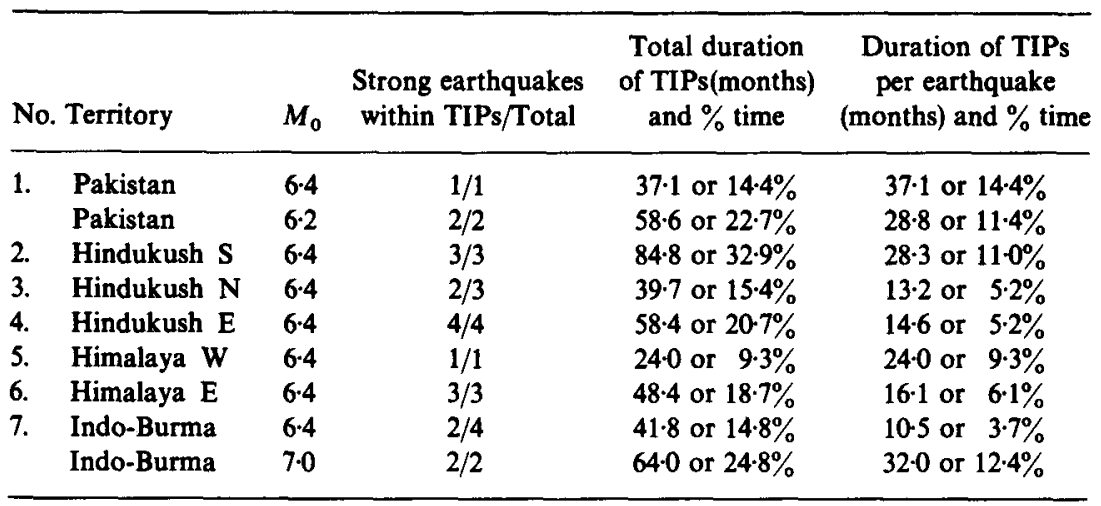


results is given in tables 2 and 3. Table 2 uses the standard values of $\bar{\Delta}$ and $\bar{\Sigma}$ (referred to in figure 3), whereas in Table 3 (referred to in figure 4) the best results are described.

The high success ratio suggests that the $\mathrm{CN}$ algorithm is well applicable in the seismic belts of the Indian plate margins using the standard parameters, and the volume of TIPs can be decreased by using higher $\bar{\Delta}$ and lower value $\bar{\Sigma}$. We strongly recommend that it should be applied in future with the updated catalogue for the purpose of short term prediction.

\section{Acknowledgements}

This research was carried out within the framework of the Pilot Activities of the International Institute for Earth, Environmental and Marine Sciences and Technologies, Trieste, Italy. We are very much thankful to Prof G F Panza and Dr V G Kosobokov for stimulating discussions. One of the authors (VKG) is thankful to Profs V K Gaur and R Chander for their encouragement and continuous interest in the problem. He is grateful to the Chairman of UGC (India) and the Head of the Earth Sciences Department, Roorkee, for their permission to visit IIEM. We extend our thanks to the directors of IIEM and ICTP for financial support. The suggestion and criticisms of the referees were helpful in improving the presentation.

\section{References}

Allen C, Hutton K, Keilis-Borok V I, Kuznetsov I V and Rotwain I M 1984 Dolgoscrochni prognoz Zemletryaseni i avtomodelnost seismologicheskih predvestinikov. Kalifornia, (Long-term earthquakes prediction and self similarity of premonitory seismicity patterns, California, $M \geqslant 6.4, M \geqslant 7$, in Russian). In Dostizheniya i problemi sovermennio geofisici (Computational Seismology issue 21 Nauka: Moskva) pp. $152-165$

Bhatia S, Vorobieva I A, Gaur V K, Levshina T A, Subedi L and Chalam S 1990 Diagnostics of times of increased probability of strong earthquakes in the Himalayan seismic belt by algorithm CN (in russian). Analysis of geophysical fields. -M.: Nauka, 1990, (Computational Seismology. Iss. 23)

Gabrielov A M et al 1986 Algorithms of long term earthquakes prediction, International School for Research oriented to Earthquake Prediction Algorithms, Software and Data Handling. (Lima, Peru, September, 1986)

Gelfand I M, Guberman Sh A, Keilis-Borok V I, Knopoff L, Press F, Ranzman E Ya, Rotwain I M and Sadowsky A M 1976 Pattern recognition applied to epicenters in California; Phys. Earth. Planet. Inter. 11 227-283

Keilis-Borok V I, Knopoff L, Rotwain I M and Sidorenko T M 1980 Bursts of seismicity as long-term precursors of strong earthquakes; $J$. Geophys. Res. 85 803-811

Keilis-Borok V I, Knopoff L, Rotwain I M and Allen C R 1988 Intermediate-term prediction of occurrence times of strong earthquakes; Nature 335 690-694

Keilis-Borok V I and Rotwain I M 1990 Diagnosis of time of increased probability of strong earthquakes in different regions of the world: algorithm CN; Physics of the Earth and Planetary Interiors. 61 57-72

Preliminary determination of earthquakes, Jan. 1991-Aug. 1991

World's hypocenters data file 1900-1991, USGS-NEIC, USA, 1990 